\title{
Electronic structure and optical properties of $\mathrm{ABP}_{2} \mathrm{O}_{7}$ double phosphates
}

\author{
Yu. Hizhnyi ${ }^{1 *}$, O. Gomenyuk ${ }^{1}$, S. Nedilko $^{1}$, A. Oliynyk ${ }^{1}$, B. Okhrimenko ${ }^{1}$, \\ V. Bojko ${ }^{2}$ \\ ${ }^{1}$ Faculty of Physics, Kyiv National Taras Shevchenko University2, block 1, Acad. Hlushkova ave., 03680, Kyiv, Ukraine \\ ${ }^{2}$ National Agriculture University, 5 Geroiv Oborony st., 03041, Kyiv, Ukraine
}

Elsevier use only: Received date here; revised date here; accepted date here

\begin{abstract}
Luminescence and luminescence excitation under VUV radiation of $\mathrm{ABP}_{2} \mathrm{O}_{7}(\mathrm{~A}=\mathrm{Na}, \mathrm{K}, \mathrm{Cs} ; \mathrm{B}=\mathrm{Al}$, In) double phosphates are studied. Two emission bands peaking near 330 and $420 \mathrm{~nm}$ are common for investigated $\mathrm{ABP}_{2} \mathrm{O}_{7}$ crystals. The band structure and partial densities of electronic states of perfect $\mathrm{KAlP}_{2} \mathrm{O}_{7}, \mathrm{LiInP}_{2} \mathrm{O}_{7}$ and $\mathrm{NaTiP}_{2} \mathrm{O}_{7}$ crystals are calculated by the full-potential linear-augmented-plane-wave (FLAPW) method. It is found that the structures of the conduction bands of $\mathrm{ABP}_{2} \mathrm{O}_{7}$ crystals, which have different $\mathrm{B}$ cations, are appreciably different. Experimental results are compared with results of calculations of the electronic structure. Assumptions concerning the origin of luminescence in double phosphates are made.
\end{abstract}

Keywords: double phosphate crystals, luminescence

\section{Introduction}

Crystals of double phosphates with general formula $\mathrm{ABP}_{2} \mathrm{O}_{7}$ belong to the family of complex phosphates of the alkaline (A) and polyvalent (B) metals. Complex phosphates are well known as perspective multifunctional materials (Dorenbos et al., 2003; Nakamura et al., 2003). Some of them are promising laser materials (Mansuy et al., 2004; Nakashima et al., 2005; Jabelica-Robert and Tarte,
1982). Complex phosphates activated with RE ions are considered as perspective scintillators or phosphor materials (Horchani et al., 2001; Finke et al., 1994; Moine and Bizarri, 2006), and, in particular, when activated with cerium, praseodymium or ytterbium ions, as fast scintillators (Wisniewski et al., 2003).

Comparatively large volume of experimental data on the optical properties of double phosphates was accumulated by now. However, there is a considerable lack of the theoretical background for explanation of experimental results. The electronic structure calculations of $\mathrm{ABP}_{2} \mathrm{O}_{7}$

*Corresponding author. Tel.: +38 044526 6278; fax: +38 044526 6278; e-mail: hizhnyi@univ.kiev.ua. 
crystals can substantially improve our understanding of the optical processes in the whole class of complex phosphate compounds.

This work continues our previous theoretical and experimental studies of $\mathrm{ABP}_{2} \mathrm{O}_{7}$ phosphate crystals (Gaididei et al., 2005; Nedilko et al., 2005; Hizhnyi et al., 2006). In this paper we present results of the electronic structure calculations and experimental measurements of

The polycrystalline samples of investigated $\mathrm{ABP}_{2} \mathrm{O}_{7}$ crystals were grown by the "melting solution" method (details of the growth are presented in Nedilko et al., 2005; Hizhnyi et al., 2006). Emission spectra of $\mathrm{ABP}_{2} \mathrm{O}_{7}$ samples under excitation with synchrotron radiation in $4-20 \mathrm{eV}$ energy region were obtained on SUPERLUMI station at HASYLAB (DESY), Hamburg, Germany.

The electronic structures of perfect $\mathrm{KAlP}_{2} \mathrm{O}_{7}, \mathrm{LiInP}_{2} \mathrm{O}_{7}$ and $\mathrm{NaTiP}_{2} \mathrm{O}_{7}$ are calculated. Potassium aluminium $\mathrm{KAlP}_{2} \mathrm{O}_{7}$ pyrophosphate and sodium titanium diphosphate $\mathrm{NaTiP}_{2} \mathrm{O}_{7}$ have monoclinic lattice with space group $\mathrm{P} 2_{1} / \mathrm{c}$. The lattice parameters are $a=7.3080, b=9.6620, c=8.0250$, $\beta=106.6900$ for $\mathrm{KAlP}_{2} \mathrm{O}_{7}$ (Hok Nam Ng and Calvo, 1973), and $a=8.6970, \quad b=5.2390, \quad c=13.2930, \quad \beta=116.54$ for $\mathrm{NaTiP}_{2} \mathrm{O}_{7}$ (Leclaire et al., 1988). Lithium indium diphosphate $\mathrm{Linn}_{2} \mathrm{O}_{7}$ is characterized by the space group $\mathrm{P} 2{ }_{1}$ and lattice parameters $a=7.0842, b=8.4362, c=4.9083$, $\beta=110.75$ (Duc Tran Qui et al., 1987).

Calculations were performed using the WIEN2k package (Blaha et al., 2001) in which the full-potential linear-augmented-plane-wave (FLAPW) method is implemented within the framework of density-functional theory (DFT). The Perdew and Wang generalized gradient approximation was employed (Perdew and Wang, 1992) for the exchange-correlation potential. The relativistic effects were treated in the scalar relativistic approximation. The energy of separation between core and valence states was chosen as $-6.0 \mathrm{Ry}$. The muffin-tin (MT) radii $R_{\mathrm{MT}}$ were chosen as 1.75 and 2.6 a. u. for $\mathrm{Li}$ and $\mathrm{K} ; 1.65,1.86$ and 1.7 a.u. for $\mathrm{Al}$, In and Ti respectively; 1.33 a.u. for $\mathrm{P}$ and $\mathrm{O}$. The potential and charge density in the MT-spheres were expanded in spherical harmonics with $l_{\max }=10$. The plane wave cutoff parameter $R_{\mathrm{MT}} K_{\max }$ was equal to 6.0. The magnitude of the largest vector $\mathrm{G}_{\max }$ in charge density Fourier expansion was 14.0.

The convergence criterion was chosen as the total energy convergence set as $0.0001 \mathrm{Ry}$. The modified tetrahedron method (Blochl et al., 1994) was used for the Brillouin zone (BZ) integration. Self-consistency was achieved using 20,30 and $50 \mathrm{k}$-points in the irreducible part of the BZ. We ascertained that the band structure and density of states calculated using 30 and $50 \mathrm{k}$-points are only slightly different. In this paper we present the results obtained for $50 k$-points.Partial densities of electronic states (PDOS) were calculated using well-known technique implemented in the WIEN2k package, which uses Gaussian smearing functions (Blaha et al., 2001). emission of double phosphates under excitation with synchrotron radiation. We intend to look into the origin of luminescence in $\mathrm{ABP}_{2} \mathrm{O}_{7}(\mathrm{~A}=\mathrm{Na}, \mathrm{K}, \mathrm{Cs} ; \mathrm{B}=\mathrm{Al}$, In $)$ crystals comparing theoretical and experimental results.

\section{Details of experiment and calculations}

\section{Results and discussion}

In our previous paper we carried out a comparative study of $\mathrm{ABP}_{2} \mathrm{O}_{7}$ double phosphates with different $\mathrm{A}$ cations ( $\mathrm{A}=\mathrm{Li}, \mathrm{Na}, \mathrm{K}$, see Hizhnyi et al., 2006). We found that the electronic structures and reflectance spectra of

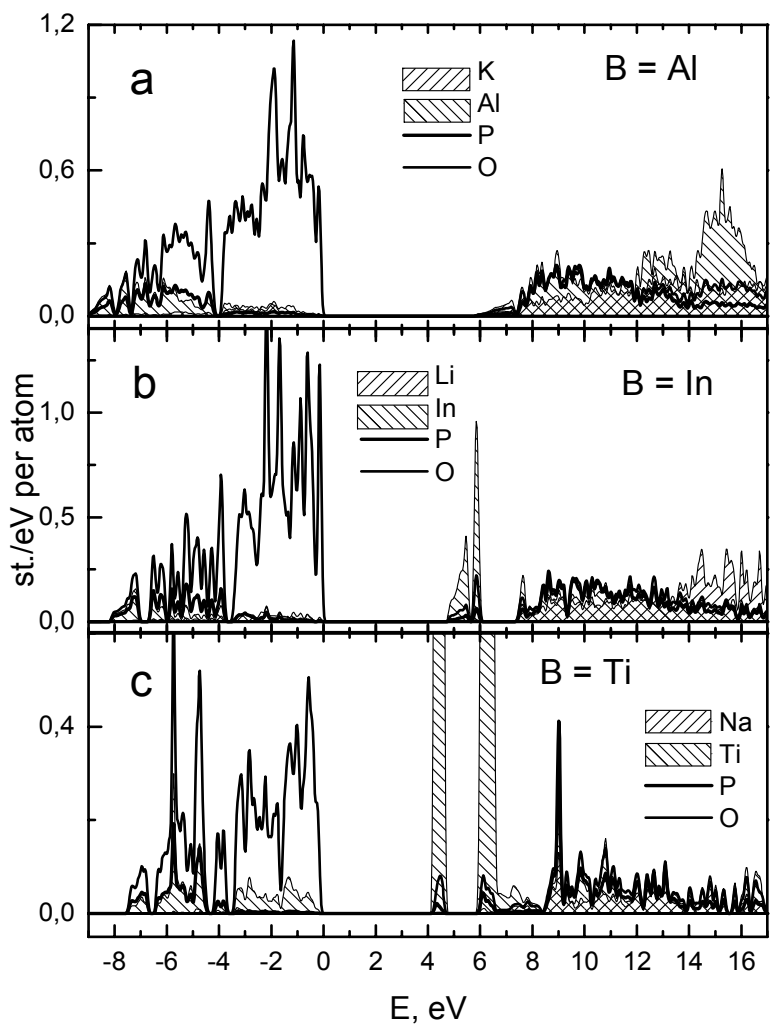

$\mathrm{ABP}_{2} \mathrm{O}_{7}$ crystals with different $\mathrm{A}$ but the same $\mathrm{B}$ cations are in great measure similar. In this paper we compare the properties of $\mathrm{ABP}_{2} \mathrm{O}_{7}$ crystals with different $\mathrm{B}$ cations.

Calculated partial densities of electronic states (PDOS) for $\mathrm{KAlP}_{2} \mathrm{O}_{7}, \mathrm{LiInP}_{2} \mathrm{O}_{7}$ and $\mathrm{NaTiP}_{2} \mathrm{O}_{7}$ are presented in Fig. $1 \mathrm{a}, 1 \mathrm{~b}$ and $1 \mathrm{c}$ respectively.

Fig. 1. Comparison of $\mathrm{PDOS}$ for $\mathrm{ABP}_{2} \mathrm{O}_{7}$ double phosphates with different $\mathrm{B}$ cations: $\mathrm{B}=\mathrm{Al}(\mathrm{a}), \mathrm{In}(\mathrm{b})$ and $\mathrm{Ti}(\mathrm{c}) ; \mathrm{A}=\mathrm{K}(\mathrm{a}), \mathrm{Li}(\mathrm{b})$ and $\mathrm{Na}(\mathrm{c})$. 
The origin of the energy scale in each figure is chosen at the top of the valence bands (VB) of corresponding crystal. As it is seen from the figure, the structures of the VBs of three crystals are in general similar. The oxygen states clearly dominate in the upper part of the VBs $(-4-0 \mathrm{eV})$. Contributions of states of phosphorus and the $\mathrm{B}$ cations are more considerable in the lower part of the VB of each crystal, below $\sim-4 \mathrm{eV}$. The average level of the oxygen PDOS curve in the case of $\mathrm{NaTiP}_{2} \mathrm{O}_{7}$ is nearly two times lower than for $\mathrm{KAlP}_{2} \mathrm{O}_{7}$ and $\mathrm{LiInP}_{2} \mathrm{O}_{7}$.

The structures of the conduction bands (CB) of three crystals are appreciably different. In the case of $\mathrm{KAlP}_{2} \mathrm{O}_{7}$ the densities of states increase almost steadily starting from $6 \mathrm{eV}$, whereas the $\mathrm{CBs}$ of $\operatorname{LiInP}_{2} \mathrm{O}_{7}$ and $\mathrm{NaTiP}_{2} \mathrm{O}_{7}$ have sub-bands clearly separated from the main parts of the CBs. Such sub-band of $\mathrm{LiInP}_{2} \mathrm{O}_{7}$ is formed mainly by the In states with considerable contribution of the $\mathrm{O}$ states and with some content of the $\mathrm{P}$ states as well. In the case of $\mathrm{NaTiP}_{2} \mathrm{O}_{7}$ two intensive peaks of the titanium PDOS are located at $\sim 4.4$ and $\sim 6.3 \mathrm{eV}$ (intensities in maxima are 5.0 and $2.6 \mathrm{st} . / \mathrm{eV}$ respectively that is outside the scale of Fig. 1c). The low-energy peak corresponds to a separated subband in $4.1-4.7 \mathrm{eV}$ region. Content of cationic and anionic states is approximately equal in the main parts of $\mathrm{CBs}$ of $\mathrm{LiInP}_{2} \mathrm{O}_{7}$ and $\mathrm{NaTiP}_{2} \mathrm{O}_{7}$ (compare Fig. $1 \mathrm{~b}$ and $1 \mathrm{c}$ ).

In this paper we intend to analyze experimental emission and excitation spectra of Al- and In-contained double phosphates taking into account the results on the electronic structure. Since the energy gaps $E_{g}$ of these crystals are different, (details of the $E_{g}$ evaluation are presented in (Hizhnyi et al., 2006)), a substantial difference of experimental optical properties of Al- and In-contained $\mathrm{ABP}_{2} \mathrm{O}_{7}$ should be expected.

Emission spectra of $\mathrm{KAlP}_{2} \mathrm{O}_{7}, \mathrm{CsAlP}_{2} \mathrm{O}_{7}$ and $\mathrm{NaInP}_{2} \mathrm{O}_{7}$ crystals obtained under excitation with various excitation energies are presented in Fig. 2.

Fig. 2. Emission of $\mathrm{KAlP}_{2} \mathrm{O}_{7}$ (a), $\mathrm{CsAlP}_{2} \mathrm{O}_{7}$ (b) and $\mathrm{NaInP}_{2} \mathrm{O}_{7}$ (c) obtained under synchrotron excitation with $\mathrm{E}_{\mathrm{exc}}=9.84$ (1), 7.08 (2), 5.87 (3), 5.23 (4), $6.52(5), 7.04$ (6) and $6.60(7) \mathrm{eV}$ at 10 (1-6) and $300(7) \mathrm{K}$.

It is clearly seen that emission of each crystal is complex, i.e. consist of several bands. We indicated the peak positions of two short-wavelength bands (denoted as I and II) of each crystal by arrows in Fig. 2.

Emission bands I and II dominate in emission spectra of $\mathrm{KAlP}_{2} \mathrm{O}_{7}$ under excitation in regions of band-to-band transitions and of the fundamental absorption edge. Excitation in the region of fundamental absorption edge of $\mathrm{CsAlP}_{2} \mathrm{O}_{7}$ causes emission mainly in band I. Emission band $\mathrm{I}$ of the In-contained crystal $\left(\mathrm{NaInP}_{2} \mathrm{O}_{7}\right)$ lies at longer wavelengths, at $415 \mathrm{~nm}$. The excitation spectrum of this band is formed by the electronic transitions from the top of the VB to the edge of the main part of the $\mathrm{CB}$ of $\mathrm{NaInP}_{2} \mathrm{O}_{7}$.
Its intensity at low temperature is high and decreases by a factor of 14 with increase of temperature to $300 \mathrm{~K}$. Mentioned above features are typical for emission of selftrapped exciton.

Emission band II in the case of Al-contained crystals accompanies band I with long-wavelength shift of the same order $\left(5300\right.$ and $6900 \mathrm{~cm}^{-1}$ for $\mathrm{KAlP}_{2} \mathrm{O}_{7}$ and $\mathrm{CsAlP}_{2} \mathrm{O}_{7}$ respectively). This emission probably originates from emission of exciton related to some defect, which is of the same type in both lattices.

Excitation with energies below $\mathrm{E}_{\mathrm{g}}$ causes emission at longer wavelengths with respect to bands I and II (Fig. 2, curves 3-5). This emission can be related to lattice defects. $\mathrm{CsAlP}_{2} \mathrm{O}_{7}$ crystals obviously have better quality than $\mathrm{KAlP}_{2} \mathrm{O}_{7}$ that determine relatively low contributions of the defect-related bands into emission spectra (Fig. 2, curve 4).

Excitation spectra confirm the presented above interpretation of $\mathrm{ABP}_{2} \mathrm{O}_{7}$ emission. Indeed, peaks in excitation at $6.9,6.6$ and $7.0 \mathrm{eV}$ dominate in excitation spectra of $\mathrm{KAlP}_{2} \mathrm{O}_{7}, \mathrm{CsAlP}_{2} \mathrm{O}_{7}$ and $\mathrm{NaInP}_{2} \mathrm{O}_{7}$ respectively (Fig. 3). As it was mentioned above, according the results of calculations, these peaks correspond to transitions into the region of the bottom of the $\mathrm{CB}$ of $\mathrm{KAlP}_{2} \mathrm{O}_{7}\left(\mathrm{CsAlP}_{2} \mathrm{O}_{7}\right)$ and into the bottom of the main part of the $\mathrm{CB}$ of

$300 \quad 400 \quad 500 \quad 600 \quad 700 \quad 8009001000$

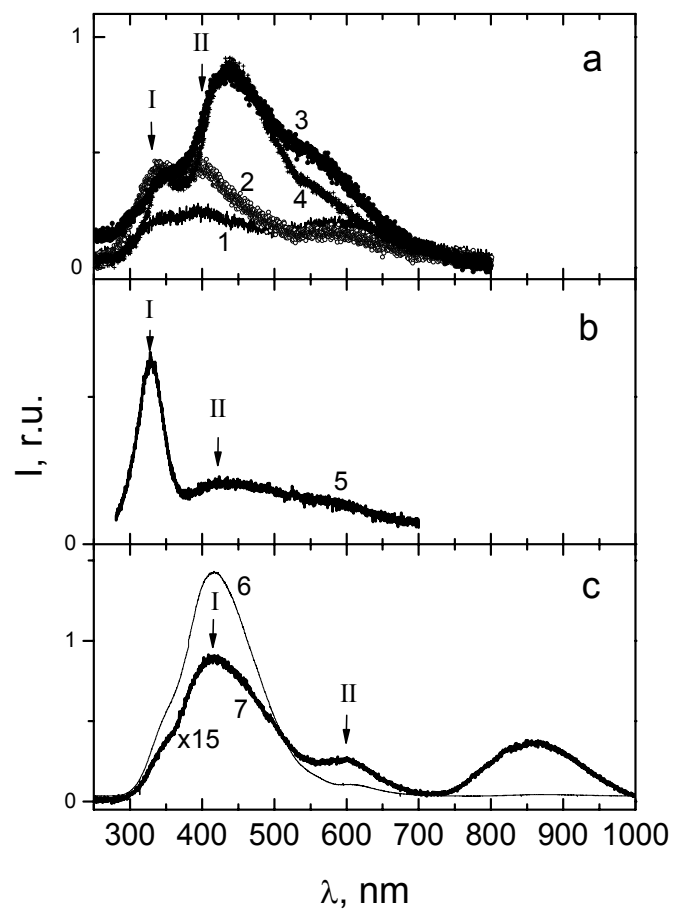

$\mathrm{NaInP}_{2} \mathrm{O}_{7}$. The $\sim 0.3 \mathrm{eV}$ value of low-energy shift of $\mathrm{CsAlP}_{2} \mathrm{O}_{7}$ excitation peak with respect to the peak of $\mathrm{KAlP}_{2} \mathrm{O}_{7}$ can evidence the difference in the $\mathrm{E}_{\mathrm{g}}$ values of these crystals. However, further calculations are necessary to confirm this assumption. Peak in excitation of band I, 
which mean absorption in the energy regions of the forbidden gap (below $6 \mathrm{eV}$ ) is observed at 5.4 and $4.9 \mathrm{eV}$ or $\mathrm{AAlP}_{2} \mathrm{O}_{7}$ crystals with $\mathrm{A}=\mathrm{K}$ and $\mathrm{Cs}$ respectively. This peak can be a consequence of direct excitation of centers, which form emission band II (Fig. 1a, 1b).

Excitation spectra of long-wavelength emissions (band II and other bands) of $\mathrm{AAlP}_{2} \mathrm{O}_{7}(\mathrm{~A}=\mathrm{K}, \mathrm{Cs})$, as it follows from comparison between experimental (Fig. 2b) and theoretical (Fig. 1a, 1b) data, fall into the energy region of the forbidden gaps. This obviously confirms the defect nature of corresponding emission centers.

Excitation spectra of $\mathrm{NaInP}_{2} \mathrm{O}_{7}$ (Fig. 3c) appreciably differ from the spectra of two Al-contained phosphate crystals

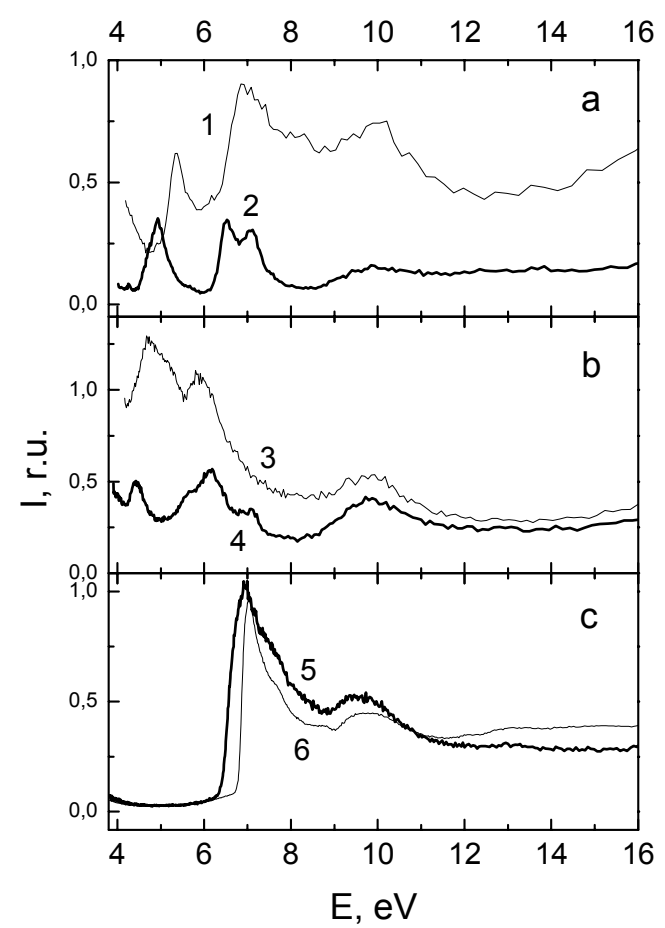

below $6.5 \mathrm{eV}$. There are entirely no bands in excitation of

Fig. 3. Excitation of emission bands I (a, c) and II (b) of $\mathrm{KAlP}_{2} \mathrm{O}_{7}$ $(1,3), \mathrm{CsAlP}_{2} \mathrm{O}_{7}(2,4)$, and $\mathrm{NaInP}_{2} \mathrm{O}_{7}(5,6)$ obtained at 10 (1-5) and $300 \mathrm{~K}(6) ; \lambda_{\mathrm{reg}}=340(1), 330(2), 460(3), 470(4)$, and $420 \mathrm{~nm}$ $(5,6)$.

emission band I in $4.7-6.3 \mathrm{eV}$ region. As it can be seen from calculated PDOS of $\mathrm{NaInP}_{2} \mathrm{O}_{7}$ (Fig. 1b), transitions from the top of the valence band to the low-energy subband of the conduction band have transition energies in 4.5 $-6 \mathrm{eV}$ range. There is a full reason to suppose that if the states that form so relatively narrow and separated subband participated in excitation of band I, a corresponding peak in excitation spectrum should appear between 4.5 and $6 \mathrm{eV}$. However, this is not the case.

In should be noted that emission spectrum of $\mathrm{NaInP}_{2} \mathrm{O}_{7}$ reveals an infrared band peaking at $870 \mathrm{~nm}$ (Fig. 2, curve
5). Equipment of SUPERLUMI does not permit registration of IR radiation in regime of excitation spectra registration. Therefore, we were not able to clarify the spectral regions of excitation of this emission. Thus, the question of its origin remains open. Nevertheless, we can suppose that the $870 \mathrm{~nm}$ emission band of $\mathrm{NaInP}_{2} \mathrm{O}_{7}$ can be related to the mentioned above sub-band (Fig. 1b) formed mainly by the In states. However, this question requires further studies.

More accurate determination of composition and the electronic structure of emission centers in $\mathrm{ABP}_{2} \mathrm{O}_{7}$ crystals is the subject of our future work..

Acknowledgements. This work was supported by STCU Project 2042.

\section{References}

Blaha P., Schwarz K., Madsen G., Kvasnicka D., Luitz J., 2001. WIEN2k, An Augmented Plane Wave Local Orbitals Program for Calculating Crystal Properties, Karlheinz Schwarz, Techn. Universitadt Wien, Austria, 2001, ISBN 3-9501031-1-2.

Blochl P.E., Jepsen O., Andersen O.K. 1994. Improved tetrahedron method for Brillouin-zone integrations. Phys. Rev B 49, 16223-16233.

Dorenbos P., Pierron L., Dinca L., van Eijk C.W.E., Kahn-Harari A., Viana B., 2003. 4f-5d spectroscopy of $\mathrm{Ce}^{3+}$ in $\mathrm{CuBPO}_{5}$, $\mathrm{LiCaPO}_{4}$ and $\mathrm{Li}_{2} \mathrm{CaSiO}_{4}$. J. Phys.: Condens. Matter. 15, 511515.

Duc Tran Qui, Hamdoune S., le Page Y., 1987. Synthese et structure cristalline de $\mathrm{LiInP}_{2} \mathrm{O}_{7}$. Acta Cryst. 43, 201-202.

Finke B., Schwarz L., Gurtler P., Kraas M., Joppien M., Becker J., 1994. Optical properties of potassium rare earth orthophosphates of the type $\mathrm{K}_{3} \mathrm{RE}\left(\mathrm{PO}_{4}\right)_{2}$. J. Lumin. 60-61, 975-978.

Gabelica-Robert M., Tarte P., 1982. New pyrophosphates $\mathrm{M}^{\mathrm{I}} \mathrm{M}^{\mathrm{III}} \mathrm{P}_{2} \mathrm{O}_{7}$. Sol. St. Chem. 3, 475-479.

Gaididei G.I., Gomenyuk O.V., Nedelko S.G., Sleptsov A.A., Antraptseva N.M., Boiko V.V., Tkachova N.V., 2005. Luminescence and vibration spectra of zinc manganese diphosphates. Phys. Sol. St. 47, 1544-1547.

Hizhnyi Yu. A., Oliynyk A., Gomenyuk O., Nedilko S.G., Nagornyi P., 2006. Electronic structure and optical properties of $\mathrm{ABP}_{2} \mathrm{O}_{7}(\mathrm{~A}=\mathrm{Na}, \mathrm{Li})$ double phosphates, to be published in Optical Materials as Proc. of Intern. Conf. IWASOM-2006, June 11-14, 2006, Gdansk, Poland.

Hok Nam Ng and Calvo C., 1973. The crystal structure of $\mathrm{KAlP}_{2} \mathrm{O}_{7}$. Can. J. Chem. 51, 2613-2620.

Horchani K., Gacon J. C., Dujardin C., Garnier N., Garapon C., Ferid M., Trabelsi-Ayedi M., 2001. Luminescence properties of $\mathrm{CsPrP}_{4} \mathrm{O}_{12}$ and $\mathrm{RbPrP}_{4} \mathrm{O}_{12}$. J. Lumin. 94-95, 69-72.

Leclaire A., Benmoussa A., Borel M.M., 1988. Two forms of sodium titanium (III) diphosphate. J. Sol. St. Chem. 77, 299305.

Mansuy C. , Nedelec J.M., Mahiou R., 2004. Molecular design of inorganic scintillators: from alkoxides to scintillating materials. J. Mater. Chem. 14, 3274-3280.

Moine B., Bizarri G., 2006. Why the quest of new rare earth doped phosphors deserves to go on. Optical Materials 28, 58-63. 
Nakamura T., Takeyama T., Takahashi N., Jagannathan R., Karthikeyani A., Smith G.M., Riedi P.C., 2003. High frequency EPR investigation of X-ray storage $\mathrm{SrBPO}_{5}: \mathrm{Eu}$ phosphor. J. Lumin. 102-103, 369-373.

Nakashima K., Takami M., Ohta M., Yasue T., 2005.

Thermoluminescence mechanism of dysprosium-doped $\beta$ tricalcium phosphate phosphor. J. Lumin. 111, 113-120

Nedilko S., Gomenyuk O., Slobodyanik N., Stus' N., 2005.

Luminescence centers generated by chromium ions in potassium-aluminum (indium) diphosphates. Phys. Sol. St. 47, 1576-1578.

Perdew J.P., Wang Y., 1992. Accurate and simple analytic representation of the electron-gas correlation energy. Phys. Rev. B 45, 13244-13249.

Wisniewski D., Wojtowicz A. J., Drozdowski W., Farmer J. M., Boatner L. A., 2003. $\mathrm{Rb}_{3} \mathrm{Lu}\left(\mathrm{PO}_{4}\right)_{2}$ : $\mathrm{Ce}$ and $\mathrm{Cs}_{3} \mathrm{Lu}\left(\mathrm{PO}_{4}\right)_{2}: \mathrm{Ce}-$ new promising scintillator materials. Cryst. Res. Technol. 38, 275-279. 